\title{
A religiosidade como elemento do desenvolvimento humano
}

\author{
The religiosity as human development element
}

\section{Le religiosité humaine element de développement}

\author{
La religiosidad desarrollo humano \\ Clacir José Bernardi* \\ Maria Augusta de Castilho*
}

Recebido em 18/07/2016; revisado e aprovado em 12/09/2016; aceito em 12/10/2016

DOI: http:/ / dx.doi.org/10.20435/1984-042X-2016-v.17-n.4(15)

\begin{abstract}
Resumo: Este estudo analisa e interpreta a religiosidade em seu contexto territorial, buscando apreender as identidades coletivas e a dinâmica da religião como propriedades dessas identidades. A pesquisa pautou-se no método dedutivo, e as fontes que a viabilizaram foram: jornais, sites, livros, artigos, interpretadas à luz das categorias da religiosidade. Se a religião está ligada a uma cultura, ela é importante para determinar essa cultura. Ao sacralizar o mundo, o homem religioso atribui à significação plena de um espaço sagrado em oposição a todo o resto, como sendo sem forma e sentido.
\end{abstract}

Palavras-chave: religiosidade; território; desenvolvimento humano; cultura.

Abstract: The study analyzes and interprets religiosity in its territorial context, seeking to understand the collective identities and the dynamics of religion as properties of these identities. The research was based on deductive method and sources that were made possible: newspapers, websites, books, articles, interpreted in the light of the religious categories. If religion is linked to a culture it is important to determine this culture. To enshrine the world, the religious man gives the full meaning of a sacred space as opposed to all the rest, as being without form and meaning. Key words: religiosity; territory; human development; culture.

Résumé: L'étude analyse et interprète la religiosité dans son contexte territorial, en cherchant à comprendre les identités collectives et la dynamique de la religion en tant que propriétés de ces identités. La recherche a été basée sur la méthode déductive et des sources qui ont été rendu possible: les journaux, les sites Web, des livres, des articles, interprété à la lumière des catégories religieuses. Si la religion est liée à une culture, il est important de déterminer cette culture. Pour consacrer le monde, l'homme religieux donne la pleine signification d'un espace sacré, par opposition à tout le reste, comme étant sans forme et signification.

Mots-clés: religiosité; territoire; le développement humain; culture.

Resumen: El estudio analiza e interpreta la religiosidad en su contexto territorial, buscando entender las identidades colectivas y la dinámica de la religión como propiedades de estas identidades. La investigación se basó en el método deductivo y fuentes que fueron posibles: periódicos, sitios web, libros, artículos, interpretado a la luz de las categorías religiosas. Si la religión está vinculada a una cultura es importante para determinar esta cultura. Para consagrar el mundo, el hombre religioso da el significado completo de un espacio sagrado a diferencia de todos los demás, por carecer de forma y significado.

Palabras clave: religiosidade; território; desarrollo humano; cultura.

\section{INTRODUÇÃO}

O Desenvolvimento Local (DL) é um processo no qual as relações humanas têm que ser levadas em consideração. Esse processo valoriza o homem, todos os habitantes do local, envolvendo a comunidade em rede que se amplia chegando a uma realidade planetária.

Como o DL envolve inúmeras reflexões, entre elas está o entendimento da religiosidade: suas manifestações, seus rituais, seus valores, seus conceitos

\footnotetext{
* Universidade Católica Dom Bosco (UCDB), Campo Grande, Mato Grosso do Sul, Brasil.
} 
e atitudes que são fundamentais para a vivência cotidiana do indivíduo.

A religiosidade constrói um universo de reflexão todo especial na vida seja individual ou social por envolver um contrato, em que o elemento esperança e sentido da vida são fundamentais para o desenvolvimento do ser humano em sua trajetória terrestre.

Na América Latina, a religiosidade tem sido construída a partir da totalidade europeia sobre a 'alteridade' ameríndia e negra, como reflete Dussel (1980), Zea (2005), e também é percebido no resgate das críticas de Frei Bartolomeu de Las Casas (2011) e de Francisco de Vitória, um expoente de Salamanca (Espanha) ao abordar o período colonial dentro da Escolástica Barroca (PICH, 2012).

Mesmo assim, construiu-se uma religiosidade profunda em diferentes regiões como corolário de uma cultura que se forma nos porões da colonização, nos escondidos das repúblicas, mas que explode em rituais, devoções, romarias, danças, além de ter uma iconografia própria, como templos suntuosos e/ou modestos. Tais manifestações estão ligadas à vida, ao espaço local e ao território como elemento formador do todo do homem.

Nesse caminho, procuram-se elementos que permitam entender o ser humano na sua localidade e a importância de se ter uma religião que atenda o indivíduo em sua plenitude.

\section{ASPECTOS CONCEITUAIS}

A formação do ser humano está ligada à construção do lugar onde ele habita que envolve desde o ambiente natural (paisagem natural) até as influências que ele recebeu na vida pretérita. Essas influências formam seu caráter individual e social. Ele se constrói em um dado território e busca ser ele mesmo nesse espaço, passando a se conectar com outros indivíduos e com elementos que passam a fazer parte de seu cotidiano. Neste processo encontram-se aspectos de sua formação tais como: a cultura, a arte, a religião, o direito, etc.

Para se entender essa questão é preciso refletir sobre alguns elementos importantes, tais como: a formação dos valores de um determinado lugar em relação à formação étnica ou de elementos externos à etnia. Igualmente é necessária uma sincera e objetiva reflexão sobre a importância dos valores culturais.

Certamente que esse debruçar epistemológico sobre a construção dos espaços locais obedece aos valores culturais puros de um grupo que recebe constantes influências do contexto societário de inserção.

Para se comentar sobre a primeira assertiva, toma-se o texto "A ciência do costume" de Ruth Benedict (1934) afirmando que a ideia de um purismo racial é mito. Caberia igualmente discutir a questão da herança racial ou étnica. Sabe-se de um modo geral o que é a hereditariedade de pai para filho. Dentro de uma linha de família, a importância da hereditariedade é enorme. Mas a hereditariedade é um assunto de linhas de família. Fora disso é mitologia. Essa mesma autora acima citada afirma ainda que, em comunidades locais, a identidade racial é visível, mas que, em uma comunidade mais ampla, nem as características físicas permanecem, elas sofrem alterações. Nessa linha de reflexão, assim Benedict (1934, p. 18) se manifesta:

Sabemos que o cruzamento entre membros do mesmo grupo ocasiona um tipo local. Mas esta é uma situação que mal existe em nossa cosmopolita civilização [...] e quando se invoca a 'hereditariedade racial', como usualmente se faz para reunir um grupo de pessoas mais ou menos do mesmo 'status' econômico, formadas nas mesmas escolas, e lendo os mesmos periódicos, tal categoria é apenas outra versão do 'nosso grupo' e do 'grupo alheio' e não 
se refere à verdadeira homogeneidade biológica do grupo. O que realmente liga os homens entre si é a sua cultura, - as ideias, os padrões que eles têm em comum. Se em vez de escolher um símbolo, como a hereditariedade de sangue comum, e de fazer disto uma divisa, a nação voltasse sua atenção preferivelmente para a cultura que une o seu povo, ressaltando-lhe os principais méritos e reconhecendo os diferentes valores que se podem desenvolver numa cultura diferente, ela substituiria por um modo de pensar realista, uma espécie de simbolismo que é perigoso por ser ilusório.

Percebe-se que o fator cultural é muito mais importante como determinador da construção de uma paisagem local do que a pureza racial vista pela autora como mito. Está claro que, se um morador do Rio Grande do Sul, por exemplo, emigrar para o estado de Mato Grosso do Sul e casar-se com uma paraguaia, ele pode até manter parte de sua cultura e da cultura de sua esposa, mas com certeza os filhos terão valores do lugar onde moram e por isso, construirão uma paisagem própria do lugar onde estão, além de que as relações que surgirem serão diferentes das do lugar de origem dele e dela.

A identidade de cada local não é coisa fixa, " [...] mas representações e construções da realidade, fenômenos subjetivos mais do que objetivos". Afirma também que a identidade de cada local se forma a partir da memória, na qual a lembrança é fundamental para se entender os valores que informam aquele local (SEYFERTH, 2010, p. 105).

A memória é individual e coletiva levando a uma construção que se faz como amálgama de identidade/etnicidade e forma enunciados ideológicos que têm sentido para aquele local, que é um rememorar, mas esse rememorar é seletivo pelo indivíduo e pelo grupo, que deixam de lado os valores que não são mais necessários, isso é, que foram ultrapassados (SEYFERTH, 2010). Ainda para essa autora, vários aspectos fundamentais da imigração alemã em Santa Catarina, suas dificuldades, seus homens importantes, suas influências devem ser levados em consideração ao se mencionar a identidade e formação desses imigrantes. Seyferth (2010) assinala que a construção de uma identidade dos imigrantes alemães em formação por mais de cento e cinquenta anos mudou consideravelmente a paisagem da região habitada por eles.

É bom perceber que tal identidade também tem influências de elementos locais, sejam eles climáticos, econômicos ou sociais. É claro que, na região estudada de Santa Catarina, aparecem elementos da escravidão no Brasil no período do Império, da imigração italiana e da presença de açorianos em Florianópolis, SC.

Vê-se que a formação cultural tem elementos dos mais variados possíveis e não apenas do grupo que dominou a região, mas ele mesmo se deixou invadir de outros elementos que foram importantes e úteis.

Portanto busca-se refletir sobre a parte final da assertiva acima: a construção dos espaços locais em termos de obediência aos valores culturais puros de um grupo ou a recepção das constantes influências. Acredita-se que tal assertiva já esteja devidamente explicada, mas, mesmo assim, podem-se trazer à luz outros argumentos e exemplos com o texto Oliven (2009), que tem como ideia fundamental de que a identidade de um grupo é determinada por ele próprio, no espaço que ocupa, cujas fronteiras são suficientes para afirmar o como se identifica uma cultura. Para esse autor, referindo-se há tempos passados, quem estivesse fora dessa fronteira era bárbaro. Todavia, com a ampliação das relações sociais, econômicas, com a complexificação das formas de produção, com a expansão dos meios de comunicação, as identidades se constro- 
em, destroem-se e se reconstroem constantemente. Oliven $(2009$, p. 74$)$ defende que "no Brasil é muito forte a tendência de se apropriar de manifestações culturais originalmente restritas a um determinado grupo social, reelaborá-las e transformá-las em símbolos de identidade nacional".

No contexto do exemplo exposto acima, pode-se destacar que a feijoada que surgiu entre os escravos negros brasileiros, que juntavam os restos e sobras dos porcos abatidos na cozinha dos senhores de engenho, com o feijão, originou-se um prato tipicamente brasileiro, sendo hoje apreciado no círculo da mais alta da sociedade. Além disso, ela ganhou sentidos diferentes dependendo da região em que é feita.

Parcelas maiores da sociedade se apropriam, das mais deferentes formas dos elementos, de símbolos de determinados grupos, dão um novo significado e assumem o elemento como seu (OLIVEN, 2009). As identidades vão se organizando conforme o elemento valorativo que sedimenta a vida das pessoas, que fazem parte dos grupos e com isso vão organizando as paisagens. Por isso, é possível afirmar que a paisagem é fruto de uma convivência das pessoas, dos seus valores, dos seus quereres que plasmam sua identidade. Nisso percebe-se sempre uma tensão entre o local e o global que refaz constantemente essas duas dimensões da realidade fática. Dessa forma, há que se localizar no mundo, a partir do universo particular com suas próprias fronteiras, culturais, de países, étnicas, o sentido de existir do ser humano. Isso não significa que o local desaparece, mas "[...] a globalização torna o local mais importante do que nunca. Como podemos nos situar no mundo a não ser a partir do nosso território, por mais difícil que seja defini-lo?" (OLIVEN, 2009, p. 80). Nesse diapasão, o homem e a sociedade formam uma identidade própria, uma paisagem caracteristicamente unívoca e eivada dos elementos valorativos que os envolvem.
O Desenvolvimento Local é um processo que envolve as mais diferentes dimensões do ser humano e da sociedade onde ele está inserido. Essas dimensões podem ser: sociais, econômicas, culturais, artísticas, religiosas etc. Entende-se o processo como algo que valoriza o ser humano como um todo sem exclusão de ninguém daquele local. Igualmente esse processo envolve o local todo como uma rede que se amplia, visando à realidade planetária. Para isso faz-se necessário entender a identidade que move as pessoas do local.

O desenvolvimento em comento implica solidariedade ativa que, por sua vez, faz parte daquilo que se caracteriza como responsabilidade social, que é o ponto de partida de estabelecimento de acordos, compromissos e ações comuns entre indivíduos, grupos, empresas e governos para poderem preservar o ambiente, a sobrevivência humana e a satisfação que possa garantir às pessoas melhorar no seu viver.

É na comunidade que se manifestam as ações solidárias que, em termos bem práticos, devem buscar ações que possam garantir o desenvolvimento que se reflete na melhora de vida. Essa melhora tem que passar pelo ganho econômico que, nas críticas de Marx (1989), é o movimentador da vida, por isso entra-se na reflexão sobre economia. Sobre isso Pecqueur (2000) trabalha de forma clara a questão afirmando que o capitalismo criou ilhas econômicas em metrópoles manipuladoras que geram um processo de exclusão social. Além de que se pode colocar que se sedimentaram relações jurídicas determinadas por leis que dão respostas em si sem levar em consideração os mais profundos valores de solidariedade, são leis criadas por intelectuais orgânicos, nas concepções marxistas, que fazem o jogo de quem detém o poder econômico.

Boisier (2004) assinala que o Desenvolvimento Local é um processo endógeno, profundamente ligado a ele- 
mentos locais, mas não é isolado, faz parte de uma realidade mais ampla e com isso o que acontece no local tem seus reflexos muito além desse local.

As identidades locais têm que ser respeitadas e, dentro disso, o mundo da religiosidade tem função fundamental, pois é ela que permite perceber as manifestações em torno do sagrado que faz parte da vida do homem e da sociedade, onde ele está e que ajuda na construção dos valores das pessoas, das famílias e das comunidades.

O Desenvolvimento Local é sempre uma realidade promissora na medida em que produz resultados bem sucedidos de grande significado nas condições concretamente vividas. Isso só é possível se os agentes envolvidos tiverem clareza sobre a ação coletiva e solidariedade social (PECQUEUR, 2000).

Nas modernas reflexões sociológicas, quando se busca entender as relações que constroem a sociedade com todos seus valores, elementos que aglutinam e que separam controles e não se usa mais o termo indivíduo, mas trabalha-se com um termo mais apropriado para dar significação melhor, o termo é sujeito. O sujeito é parte integrante de todo o processo de entendimento da sociedade. Ele é parte das estruturas que determinam o mundo que o rodeia. Ele transforma e é transformado por essas estruturas.

É nessa relação que se formam os espaços e os territórios, é aí que se percebe a ação do sujeito que só é social quando leva em conta a ação do outro. Para Weber (1970), esta relação não é quando acontece como se fosse com um objeto, por exemplo, a relação com a chuva. Tem que ser uma ação significativa entre os sujeitos em que haja uma efetiva reciprocidade, na qual os sujeitos tornam-se atores, protagonistas de uma vida dentro de um sistema social. Eles não têm um papel programado nem atuam em uma lógica única, eles têm um lugar de encontro onde aparece o que é lugar comum.
O sujeito-ator se encontra em um ponto e, a partir desse ponto, ele vai construindo o espaço. Esse ponto não é um privilégio em relação aos outros elementos, ele é a origem da representação que fornece o suporte egocêntrico da representação na qual é a manifestação do eu em relação aos outros. Nessa assertiva, o ator vai se deslocando conforme seus interesses, intenções e relações, indo se desenvolvendo e criando o espaço. Este é construído pelo ator que comunica suas intenções e organiza uma realidade material. Essa realidade material é o território, mas o território de um ator.

Na ótica de Raffestin (1993, p. 17), "o território se forma a partir do espaço, é resultado de uma ação conduzida por um ator sintagmático (ator que realiza um programa) em qualquer nível e que o território se apropria do espaço e que o ator territorializa o espaço".

O lugar comum é o espaço que é uma construção mental em que se identificam as coisas necessárias para viver, sendo algo que existe na cabeça, algo virtual no qual se identificam as relações de convivência, os valores, os elementos que mantêm os diferentes unidos. Ele é anterior ao território, pois o território é construído a partir das noções, das potencialidades que se têm do espaço. O espaço aparece como 'prisão original', e o território é a prisão que as pessoas constroem a partir do espaço.

Assim, o ator local tem uma relação com os demais sujeitos com quem convive. Cada um dos sujeitos são atores individuais, egocêntricos que têm seus espaços e por consequência seu próprio território individual. Mas esses sujeitos estão em relação com outros sujeitos e, nessa relação, aparece algo comum que lhes permite conviver que é uma construção coletiva, que primeiro constroem um espaço coletivo e daí um território que também é coletivo no qual se "revelam objetivos intencionais congruentes, mas, contudo diferentes... resulta num 
jogo multilateral dos múltiplos atores em causa" (RAFESTTIN, 1993, p. 19).

A construção desses territórios sociais faz perceber limites, fronteiras que, ao longo da história, configuraram regiões onde se organizava um poder. Podem-se colocar os Estados Nacionais Modernos que criaram uma ideia de soberania de poder de um espaço desenvolvido em um território. Mas foi com a unificação alemã, na qual apareceu a ideia de espaço vital, que se determinou uma soberania em um território construído em um dado território.

Surge então o espaço legal que traz a necessidade de legislação específica e representa tal território que envolve solo, o povo e, junto com iss,o surge a ideia de unidade política em um território fixo e em um determinado tempo mantido, se necessário, com o uso da força. A fronteira tornou-se um ato de vontade e de força, porém, não estável, mas flutuante.

Os elementos que acabam se formando, dão coesão ao território, cujos elementos são a linguagem, as forças armadas, a legislação, a moeda etc.

Hoje se têm enormes discussões sobre a necessidade ou não das linhas de fronteira tradicionais e de todos os elementos que as constituem. Raffestin (1993) defende a ideia de abolição dessas linhas, pois as relações humanas são muito mais complexas e amplas e não podem ficar dentro de um sistema de leis, de um sistema econômico, de um sistema de linguagem. Por isso, é muito difícil determinar os territórios dentro dos limites dos Estados tradicionais, mesmo porque os espaços sociais são cada vez mais amplos e imbricados. Essas mudanças são notadas nos deslocamentos populacionais, nas constantes desterritorializações, percebendo-se inclusive o surgimento de novos valores culturais.

O território é construído conforme o espaço social de um determinado grupo de pessoas em um determinado local em que está presente a individualidade de cada um dos sujeitos-atores que são diferentes, mas têm algo em comum. Esse algo comum é a parte do território vivido que é sempre novo, pois se constrói constantemente onde se percebe o cotidiano como criador, inventivo. Os sujeitos constroem redes em micro e macroescalas, horizontalmente e verticalmente por meio de práticas inteligentes que se inovam, tornando o local habitável e sustentável.

Por isso, pode-se enfatizar que territorialidade é a multidimensionalidade do sujeito vivido em um dado território que são as relações interativas desses sujeitos em que transparecem: emoções, elos, sentimento de pertença com o lugar (ligar-se a ele). "Os homens vivem, ao mesmo tempo, o processo territorial e o produto territorial por intermédio de um sistema de relações existenciais e/ou protudivistas" (RAFESTTIN, 1993, p. 15).

A ideia de territorialidade passa pelas relações de poder, de cultura, de língua, que modificam e são modificadas pelos sujeitos. A territorialidade é uma ideia que permite conhecer a identidade dos grupos e suas imbricações na qual existe uma governança que se desenvolve em rede, é flexível, plural e permite a realização dos sujeitos que fazem parte dela.

A territorialidade é a construção de tessitura em redes que fazem os indivíduos convergir se relacionarem, mas também se desintegram e se reorganizam. "A territorialidade pode ser definida como um conjunto de relações que se originam num sistema tridimensional sociedade-espaço-tempo em vias de atingir a maior autonomia possível, compatível com os recursos do sistema" (RAFESTTIN, 1993, p. 142).

A religiosidade é um elemento fundamental para se caracterizar os valores que formam o homem e a sociedade dentro de um espaço territorial. Entender um espaço territorial é entender a cultura em que vive a sociedade de tal espaço e, junto com isso, está a religiosidade. 


\section{A RELIGIOSIDADE DO SER HUMANO E SUA VIVÊNCIA EM SOCIEDADE}

A religiosidade é a manifestação do sagrado que é a presença de uma potência sobrenatural em que se mostra o poder por meio de algum símbolo como uma força sobrenatural (CHAUÍ, 1995). Essa força, considerada superior, serve de alento às situações mais diferentes que possam acontecer no dia a dia. As representações são naturais, mas possuem um significado que as liga às teofanias em que aparece a força da potência realizadora daquilo que o homem pensa não ser capaz de resolver.

Esse sagrado envolve os seres humanos criando vínculos com o numinoso, eterno, perfeito, envolvendo não só um ser humano, mas também grupos que assumem manifestações comuns que passam a fazer parte de uma sociedade e constroem valores, que são elementos determinantes de uma cultura. Em todas as culturas, existem manifestações possíveis de expressar o sobrenatural que faz parte de suas vidas.

A força pode representar qualidade boa ou má, Deus do bem e Deus do Mal, mostrando que o sagrado é não só o bem e pode levar aspectos positivos, mas é também algo que causa medo, e esse medo nada mais é do que a força que deixa sempre em alerta a necessidade de se garantir atos bons para evitar as ações desse malvado. Dai a suscitação de devoções que podem ser boas (amor, fraternidade...) e más (ódio, repulsa etc.).

O sagrado, como manifestação de força, de potência, está para ajudar a superar as dificuldades ou para quem tem medo, indicar o caminho que não se deve seguir. Tais manifestações religiosas podem se expressam nas relações individuais ou coletivas.

Desde os conceitos mais tradicionais que colocam a religião como religação, vinculação do profano ao sagrado, bus- cando onde estão as divindades, até as noções mais modernas que descartam as necessidades de se ter elemento de ligação entre indivíduos para se ter a ligação com o sagrado. Percebe-se que são uma manifestação de um dado local, dentro de um território específico, em um dado tempo que pode ser econômico, social, histórico etc. A religião desenvolve uma ideia de espaço sagrado onde a teofania acontece e ela mesma mostra como deve ser o espaço sagrado dando qualidades culturais que são diferentes das qualidades naturais.

Religião, manifestação do sagrado, acontece em um espaço cultural.
A cultura pode ser definida como a totalidade das reações e ativida- des mentais e físicas que caracte- rizam a conduta dos indivíduos que compõem um grupo social, coletiva e individualmente, em relação ao seu ambiente natural, a outros grupos, a membros do mesmo grupo e de cada indiví- duo para consigo mesmo. (BOAS, 2010, p. 113).

Tem que se colocar que cultura e religião se desenvolvem juntas e que uma influencia no desenvolvimento da outra e vice-versa. Nas relações, os símbolos, sob o ponto de vista meramente cultural, apresentam respostas que partem dos próprios símbolos, das próprias relações. Mas, para o ponto de vista da religião, o fundamental é a fé, que faz presente a crença em algo sobrenatural e sagrado. "Com os elementos da fé não se tem como ter um controle pleno, além disso, eles exigem que se tome posição, não sendo possível ficar inerte frente às situações que a vida impõe" (SANCHES, 2010, p. 155).

Os valores culturais vão determinar quais objetos, ritos e sinais que se apresentarão como sagrados. Sanches (2004, p. 38) estabelece que "é necessário reconhecer que os conceitos religiosos se formam a partir da cultura e que a comunhão de fé é determinada pelo que envolve o todo de uma sociedade". As decisões são assim ou 
não são assim, dependendo também da crença de cada grupo social.

Se a religião está ligada a uma cultura, ela é importante para determinar essa cultura. "Um deus é a personificação de um poder motivador ou de um sistema de valores que funciona para a vida humana e para o universo" (CAMPBELL; MOYERS, 1990, p. 24); é, por isso, definidor dos valores que aquela sociedade vai adotar. Os contextos históricos são construídos com o que os homens entendem e explicam com o que é racionalmente claro, mas também são construídos pelo inexplicável que se torna um elemento de fé e, por isso, explicado pela religião.

$O$ fato de a religião ser a relação com o transcendente é compreendido na diversidade das relações humanas, envolvendo pessoas, famílias, grupos, locais e, dessa maneira, as culturas. Sanches (2010) estabelece que, na percepção da diversidade religiosa, é preciso ter um bom conhecimento de cultura para se entender a religiosidade deste ou daquele grupo, deste ou daquele espaço, nesta ou naquela cultura.

A cultura também é importante para desenvolver os valores religiosos. É onde a religião acontece e, por isso, ela é marcada pela religião. Rampazzo (1996, p. 51) enfatiza que "todas as tribos e todas as populações de qualquer nível cultural, cultivaram alguma forma de religião", e que "todas as culturas são profundamente marcadas pela religião". Nessa vertente, evidencia-se que a religião é uma manifestação humana, não se percebendo fenômenos religiosos em outros seres, estando presente em todas as sociedades humanas independente de espaço, tempo, situação geográfica.

O religioso aparece desde as tribos mais primitivas e em qualquer nível cultural. Ao se analisar as culturas em seu espaço histórico, em sua arte, em sua economia, em seu processo de aprendizagem, identificam-se sinais culturais específicos de cada povo. O religioso é algo inerente ao ser humano como indivíduo, mas é uma manifestação deste homem na relação com os outros homens, portanto é uma manifestação cultural que se mostra na transcendência.

A religião permite conhecer o local onde as pessoas vivem seus valores em uma cultura. Ela é influenciada pela cultura, mas ela também influencia a cultura daqueles que vivem em seu entorno. A religião permite um conhecimento maior dos valores que envolvem uma dada sociedade, principalmente seus valores éticos. Ela se coloca como luz que ilumina as atitudes humanas em busca do Eterno, e não há religião em que esse eterno seja a destruição. Esclarece-se que esse caminho é ético, se bem fundamentado, permite entender o caminho que aquela sociedade está seguindo para se realizar como sociedade em busca da garantir a realização dos indivíduos que fazem parte dela.

\section{AS MANIFESTAÇÕES RELIGIOSAS NA COMUNIDADE LOCAL}

A partir do que está analisado acima, pode-se fazer algumas reflexões sobre a construção do religioso na comunidade local tentando vislumbrar pontos que permitam entender o agir das pessoas nessa comunidade.

Em se fazendo uma pequena digressão histórica na América Latina e no Brasil, percebe-se que o religioso, desde as tomadas de posse do Novo Mundo, foi uma imposição da totalidade europeia que precisavam se impor sobre as totalidades ameríndias para garantir sua preponderância cultural. Isso trouxe a destruição das totalidades ameríndias e de suas identidades locais e culturais.

A sistemática da instalação da máquina metropolitana nas colônias da América Latina, sob o signo da necessidade do acúmulo mercantilista e do controle político do absolutismo bem como da avidez de uma burguesia que se afirmava e precisava se colocar como classe hege- 
mônica, fazia necessário esse processo destruidor e desagregador das culturas, inclusive o religioso na localidade.

Mesmo assim, as culturas locais, quando se pensa em religião, desenvolveram uma amálgama que mostra a presença das mais diferentes manifestações. Faz parte disso: o universo ameríndio com seus cultos animistas na esperança dos astros como iluminadores do homem, da vida e do existir do mundo. O universo afro com sua simbologia rica e cheia de rituais onde se valoriza a produção, o corpo, a encruzilhada como ponto de encontro como afirma Santos (2012). Nesse universo afro, estão presentes os lugares da senzala (lugar da escravidão e do sofrimento), o lugar do quilombo (lugar da liberdade e do não sofrimento). Não se pode deixar fora o universo católico, que, mesmo colonizador, se adapta às adversidades e consegue se aproximar das pessoas dando importância aos valores que formam os locais.

A religião é a manifestação do sagrado que são atenuadores do “[...] terror diante da finitude da vida e impõe obediência a valores morais vitais para a sobrevivência humana" (CASTILHO, 2006, p. 148). Nesse contexto, as pessoas, os lugares, os espaços reconstroem a religiosidade que lhes é tão cara.

As manifestações religiosas que se formam a partir de uma ou várias matrizes organizam esse universo que é resposta para os temores da vida. Isso transparece em relatos místicos que se faz dos fatos que acontecem.

O ser humano tem uma grande capacidade de abstrair inúmeras respostas ao que o aflige. Desde os imemoráveis tempos bíblicos, a leitura dos fatos feita aos olhos da fé faz aparecer nas interpretações a presença do sagrado como acompanhante e solucionador das dificuldades e com a promessa de dias melhores, mesmo que sejam em tempos escatológicos.

Dessa forma, temos as mais diferentes manifestações do sagrado que, junto com situações locais (economia, formação étnica, geografia...), determina os comportamentos humanos e as formas rituais em que se mostram as teofanias.

Em todos os lugares, essa realidade se manifesta fortemente arraigada na vida das pessoas, como aparece em estudo feito em Campo Grande com algumas situações que serão aqui tratadas, mesmo que de forma superficial.

A religiosidade como elemento de esperança está presente na história das duas meninas: Fátima Aparecida Vieira, que morreu em um incêndio acidental, deu origem à devoção de visitas de seu túmulo após narrativa de milagre contado por pessoa fiel; a história de Santa Carminha, assim chamada por quem visita seu túmulo, trata-se de uma menina estuprada por seu padrinho (CASTILHO; AVER, 2006).

Nos dois casos, a santidade aparece a partir de um enorme sofrimento das 'santinhas'. É muito semelhante às santificações oficiais da Igreja Católica ligadas a sofrimentos. No catolicismo, tem-se uma 'categoria' de santos que são chamados de mártires, cujo sofrimento é alento para quem precisa de ajuda.

Essas duas meninas são as respostas que pessoas com fé buscam e conseguem. O mistério da graça se faz presente mostrando o poder do 'santo', e a teofania leva as pessoas a conseguir aquilo que solicitaram ao santo.

Em outros casos concretos, pode-se colocar a devoção de Geralda Luiza das Chagas e Florentina Armoa, que, com suas rezas, em seus espaços dão esperança aos fiéis que as procuram (CASTILHO; AVER, 2006).

Essas duas senhoras afirmam revelações do sagrado que fizeram com que elas dessem um rumo a suas vidas em que a relação com o numinoso é um elemento de santificação e que isso é exteriorizado em ações e devoções, que fazem muitas pessoas não só acreditarem como mudarem de vida. 
Ao se analisar a história do cristianismo, tem-se uma Tereza D’Ávila, que, mesmo dentro do claustro, provocou enorme devoção dos fiéis.

Não é necessária uma religião oficial para despertar o religioso que está dentro de todos. Pode-se até ter um religioso que se imponha, mas é o dia a dia, as dificuldades, os lugares, os espaços que desenvolvem o religioso como respostas em direção ao sagrado.

\section{CONSIDERAÇÕES FINAIS}

O mundo moderno vem descobrindo a importância do sagrado para a formação e desenvolvimento das cidades.

O ser humano religioso sente necessidade de viver em um espaço sagrado e conviver com coisas sagradas, por isso, constrói lugares e coloca objetos que sacraliza, ou seja, que reveste de sentimento religioso.

Evidencia-se que a religião é uma manifestação humana, não se percebendo fenômenos religiosos em outros seres, estando presente em todas as sociedades humanas independente de espaço, tempo, situação geográfica.

A vida de uma coletividade envolve crenças que se revelam nas condutas e se materializam nas formas espaciais do cotidiano vivido, o que inclui a valorização, não só da dimensão simbólica - significativa dessas condutas-, como também da dimensão cultural reveladora dessas crenças e condutas.

Assim, a organização do sagrado no território de forma endógena constitui-se em uma dinâmica, móvel no espaço. A territorialidade do sagrado seria um espaço de representação e apropriação simbólica de determinado espaço sagrado. Este é fundamental para o homem, na medida em que para ele a alma é imortal e para viver bem na terra e apresentar-se puro diante de Deus após a morte carnal.

A experiência religiosa, mesmo sendo subjetiva, contribui para a vida social, na medida em que motiva atitudes e comportamentos coletivos referentes ao sagrado, as formas espaciais resultantes exercem influência sobre a vida cotidiana da sociedade.

O comportamento religioso é direcionado pelo imaginário intuitivo e pelo sentimento religioso e emocional, revelando-se como sagrado, sob formas materiais e imateriais no contexto do território e da territorialidade.

\section{REFERÊNCIAS}

BENEDICT, Ruth. The science of custom. In: . Patterns of culture. Tradução de Olga Dória. Boston: Houghton Mifflin Company, 1934. p. 1-20.

BOAS, Frans. A mente do ser humano primitivo. Petrópolis, RJ: Vozes, 2010.

BOISIER, Sérgio. Desarrollo territorial y descentralización. El desarrollo en el lugar y en las manos de la gente. Revista Eure, Santiago de Chile, v. XXX, n. 90, p. 27-40, set. 2004. Disponível em: <http://www.scielo. $\mathrm{cl} / \mathrm{pdf} /$ eure/v30n90/art03.pdf>. Acesso em: 5 jun. 2016.

CAMPBELL, Joseph; MOYERS, Bill. O poder do mito. São Paulo: Palas Atena, 1990.

CASTILHO, Maria Augusta de. O místico da fé católica em Campo Grande - devoções populares. In: CASTILHO, M. A. (Org.). O sagrado e o místico da fé católica no contexto da territorialidade urbana em Campo Grande - MS. Campo Grande, MS: UCDB, 2006.

CASTILHO, Maria Augusta; AVER, Fernando Alessio. Devoção popular a Fátima no cemitério Santo Amaro. In: CASTILHO, M. A. (Org.). O sagrado e o místico da fé católica no contexto da territorialidade urbana em Campo Grande - MS. Campo Grande, MS: UCDB, 2006.

CHAUÍ, Marilena. Convite à Filosofia. 3. ed. São Paulo: Ática, 1995.

DUSSEL, D. Enrique. Caminhos de libertação latino-americana. São Paulo: Edições Loyola, 1980.

LAS CASAS, F. B. O paraíso destruído: a sangrenta história da conquista da América 
Espanhola. Tradução de Heraldo Barbuy. Porto Alegre: L\&PM, 2011.

MARX, Karl. A origem do capital: acumulação primitiva. 6. ed. Tradução de Walter S. Maia. São Paulo; Rio de Janeiro: Global, 1989.

OLIVEN, Rubem G. Cidades, territórios e identidade. In: CARNEIRO, Sandra S.; SANT'ANNA, Maria J. G. (Org.). Cidade: olhares e trajetórias. Rio de Janeiro: Garamond, 2009.

PECQUER, Bernard. O desenvolvimento local para uma economia dos territórios. Paris: Syros, 2000.

PICH, Roberto Hofmeister. Dominium e ius: sobre a fundamentação dos direitos humanos segundo Francisco de Vitoria (1483-1546). Revista Teocomunicação, Porto Alegre, v. 42, n. 2, p. 376-401, jul./dez. 2012.

RAFFESTIN, Claude. Por uma geografia do poder. São Paulo: Ática, 1993.

RAMPAZZO, L. Antropologia, religiões e valores cristãos. São Paulo: CEDAS/Loyola, 1996.

SANCHES, Mário Antônio. Religião e ciência: o porquê do diálogo. In: ROSSI, L. A. S.;
KUZMA, C. A. Cultura, religião e sociedade: um diálogo entre diferentes saberes. Curitiba: Champagnat, 2010. p. 155-167.

. Bioética: ciência e transcendência. São Paulo: Loyola, 2004.

SANTOS, Luis Carlos. Ancestralidade e liberdade: em torno de uma filosofia africana no Brasil. Revista Sul-Americana de Filosofia e Educação - RESAFE, n. 18, p. 48-61, maio/ out. 2012.

SEYFERTH, Giralda. Comemoração, identidade e a memória da imigração. In: FERRERA, Ademir P. (Org.). A experiência migrante: entre deslocados e reconstruções. Rio de Janeiro: Garamond, 2010.

WEBER, A. História sociológica da cultura. Tradução de M. E. Costa da Fonseca, M. M. Duarte Sequeira. São Paulo: Mestre Jou, 1970.

ZEA, Leopoldo. Discurso desde a marginalização e a barbárie - seguido de A filosofia latinoamericana como filosofia pura e simplesmente. Tradução de Luiz Gonzalo Acosta Espejo, Francisco Alcidez Candia Quintana e Maurício Delamaro. Rio de Janeiro: Garamond, 2005.

\section{Sobre os autores:}

Clacir José Bernardi: Aluno Especial do Doutorado do Programa de Pós-graduação em Desenvolvimento Local e professor do Curso de Direito da Universidade Católica Dom Bosco (UCDB). E-mail: clacir@ucdb.br

Maria Augusta de Castilho: Pós-doutorado em Linguística pela Universidade de São Paulo (USP). Professora no Programa de Pós-Graduação em Desenvolvimento Local (Mestrado/Doutorado) da Universidade Católica Dom Bosco (UCDB). E-mail: m.a.castilho@terra.com.br 
